\title{
Liposuction in Cancer-Related Lower Extremity Lymphedema: an Investigative Study for Clinical Applications
}

Jianfeng Xin

Beijing Shijitan Hospital, Capital Medical University, Beijing, China.

\section{Yuguang Sun}

Beijing Shijitan Hospital, Capital Medical University, Beijing, China.

\section{Song Xia}

Beijing Shijitan Hospital, Capital Medical University, Beijing, China.

\section{Kun Chang}

Beijing Shijitan Hospital, Capital Medical University, Beijing, China.

\section{Yiyin Li}

Beijing Shijitan Hospital, Capital Medical University, Beijing, China.

\section{Jian Dong}

Beijing Shijitan Hospital, Capital Medical University, Beijing, China.

\section{Wenbin Shen ( $\nabla$ shenwb@bjsjth.cn )}

Beijing Shijitan Hospital,Capital Medical University

\section{Research Article}

Keywords: lymphedema, lower extremity, liposuction

Posted Date: May 28th, 2021

DOl: https://doi.org/10.21203/rs.3.rs-559817/v1

License: (c) (i) This work is licensed under a Creative Commons Attribution 4.0 International License. Read Full License 


\section{Abstract}

Background: Lymphedema is a progressive, noncurable condition consisting of increases in subcutaneous fat and interstitial fluid in the limbs and fibrosis during later stages. The disease most commonly affects the limbs because of injury to or removal of lymph nodes. The aim of this study was to investigate therapeutic effects of liposuction for cancer-related lower extremity lymphedema.

Methods 62 patients with cancer-related lymphedema in unilateral lower extremity were recruited in this study, and all the patients underwent liposuction. The volume of hemorrhage and lipid, the operation time and the volume changes of affected extremity were compared by applying $t$-test, and the subjective evaluation of the patients were also assessed by applying Chi-square.

Results Total lipid volume is $(2539 \pm 1253.5) \mathrm{ml}$, and the hemorrhage volume is $(828 \pm 311.8) \mathrm{ml}$ during liposuction. For the comparison of objective indexes, (1) Comparison of percent volume difference before surgery, in-operation and 3-month follow-up was (5.5 \pm 12.2 Vs. $11.6 \pm 18.4$ Vs. $43.2 \pm 23.7, P \llbracket 0.05$ ) respectively. (2) Higher lipid volume and liposuction rate for female patients, with lower volume of hemorrhage. (3) Higher volume of hemorrhage in patients with erysipelas (4) Higher lipid volume and liposuction rate, with lower hemorrhage for stage II than stage III patients.

Conclusions Liposuction is an effective therapy for cancer-related lower extremity lymphedema, and it is necessary to combine with other therapeutic methods to improve lymph circulation.

\section{Background}

Pelvic tumor surgery is traditionally characterized by several major complications, of which secondary lower extremity lymphedema is one. Lymphedema is a disabling condition whereby damage to lymphatic channels causes accumulation of protein-rich lymphatic fluid with the subcutaneous tissues which can cause abnormal proliferation of subcutaneous adipose tissue. Liposuction refers to a surgical technique that uses various equipment to aspirate excess subcutaneous fat through small incisions made on the skin to improve body esthetics. Since Illouz[1] first reported the usage of negative pressure suction method for fat aspiration in 1980, liposuction has been widely applied in various therapeutic fields. The therapeutic effect of liposuction for lymphedema is still controversial. Brorson [2] and Boyages[3] have reported that liposuction combined with post-operative controlled compression therapy (CCT) is effective for the treatment of limb lymphedema. However, the research results of Qi[4] showed that the limb volume reduction was noted in all cases immediately after operation, but this state of volume reduction remained 3 to 12 months with a mean of 6.01 months by applying low-stretch bandages or compression stockings, subsequently it returned to the preoperative volume level. In addition, the potential surgical risks and the effects in different lymphedema patients groups has not yet been investigated.

Therefore, the primary aim of this study was to evaluate the volume of aspirated fat and the volume of blood loss during the operation in different patients groups with secondary lower extremity lymphedema 
after cancer treatment. A secondary aim was to compare the percent volume difference before surgery, inoperation and 3-month follow-up.

\section{Materials And Methods Patients}

This retrospective study was conducted after approval by the Institutional Review Board in our hospital, and a waiver of consent was obtained. The patients with lymphedema admitted to Beijing Shijitan Hospital from January to June 2017 were screened, and the inclusion criteria were as follows:(1)Patients with secondary lymphedema of unilateral lower extremity; (2) according to the lymphedema staging established by International Society of Lymphology (ISL) in 2013[5], patients were classified as either stage II or stage III; (3) the first operation was liposuction; (4) compression stockings were mandatory after surgery; (5) patients were followed up for more than 3 months. Exclusion criteria: (1) patients with stage 0 and stage I lymphedema;(2) patients with history of surgical treatment for lymphedema;(3)lower extremity lymphedema treated by liposuction combined with other surgical methods simultaneously.

A total of 62 patients were enrolled- 16 males and 46 females, whose mean age was ( $55.6 \pm 11.3)$ years(range 21-75). The mean course of disease was 55.8 months(range 12-288). Twenty-nine cases

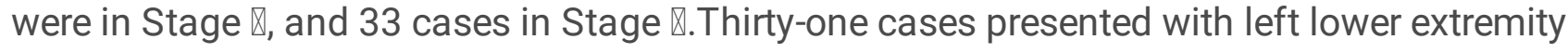
lymphedema, and 31 cases with right lower extremity lymphedema. Twenty patients had history of recurrent erysipelas, 16 with hypertension, and 4 with Type II diabetes.Secondary factors contributing to lymphedema include cervical cancer in 29 cases, endometrial cancer in 11 cases, ovarian cancer in 3 cases, testicular cancer in 3 cases, rectal cancer in 2 cases, penile cancer in 2 cases, lymphoma in 2 cases, bladder cancer in 1 case, inguinal stromal tumor in 8 cases, and inguinal trauma in 1 case.

\section{Surgical Method}

The operation was performed under general anesthesia with endotracheal intubation.Tumescent solution (formula: $0.9 \%$ normal saline $3000 \mathrm{ml}, 0.1 \%$ epinephrine hydrochloride $3 \mathrm{ml}, 2 \%$ lidocaine hydrochloride $30 \mathrm{ml}, 5 \%$ sodium bicarbonate $30 \mathrm{ml}$ ) was infused into subcutaneous adipose tissue that needs to be aspirated. Liposuction equipment with resonance and negative pressure(GZXZ resonance liposuction system, produced by YangguangZhongtian Medical Equipment Co., Ltd. in Shanxi) was utilized. At the end of liposuction, excess blood and fluid in the subcutaneous space was removed as much as possible. Circumferences of the operated limb were measured again at various points marked on its surface before operation.A Jackson-Pratt (JP) drain was placed subcutaneously to drain excess fluid. The operated limb was subsequently applied with compression bandages.At post-operative Day 3 , after dressing change and drain removal, the operated extremity was applied with compression stocking. Patient was then allowed to exercise.

\section{Measurement}

BMI BMI was calculated before and 3 months after surgery. $\mathrm{BMI}=$ weight $(\mathrm{kg}) /$ height $^{2}\left(\mathrm{~m}^{2}\right)$. 
Volume difference and percent volume difference Based on limb measurement and volume calculation method devised by Brorson $\mathrm{H}$ [6], volume difference and percent volume difference were calculated before, immediately after and 3 months after liposuction.(1) Points to be measured are marked on the body surface at the following locations: metatarsophalangeal joint, dorsum of the foot (midpoint of the arch of the foot), the ankle (anterior midpoint between medial and lateral malleolus), the knee (midpoint of the knee joint), the lower leg (lower $1 / 3$ of connecting line between the ankle marker point and the knee marker point), the middle leg (midpoint of connecting line between the ankle marker point and the knee marker point), the upper leg (upper 1/3 of connecting line between the ankle marker point and the knee marker point), the root of the thigh (anterior midpoint of the horizontal line drawn from the medial side of the thigh root, ie. at the level of the lower border of pubic symphysis), the lower thigh (lower $1 / 3$ of connecting line between the knee marker point and the thigh root marker point), the midthigh (the midpoint of connecting line between the knee marker point and the thigh root marker point), the upper thigh (upper $1 / 3$ of connecting line between the knee marker point and the thigh root marker point) (Fig. 1a). (2) The circumferences of the lower limbs were measured at the aforementioned body surface marker points. (3) The length of the legs and the thighs of both lower limbs were measured. The length of the legs is the distance from the ankle marker point to the knee marker point; the length of the thighs is the distance from the knee marker point to the thigh root marker point. (4) The volume of the lower limbs was calculated according to the circumferences measured at each body surface marker point and the length of the legs and the thighs; (5) The volume difference and percent volume difference were calculated.

Lower limb volume $=\mathbb{\pi} \boldsymbol{\pi h}\left(R_{1}^{2}+r_{1}^{2}+R_{1} \times r_{1}\right)+\nabla \pi \mathrm{h}\left(R_{2}^{2}+r_{2}^{2}+R_{2} \times r_{2}\right)+\ldots+\nabla \pi \mathrm{h}\left(R_{\mathrm{n}}{ }^{2}+r_{\mathrm{n}}{ }^{2}+R_{\mathrm{n}} \times r_{\mathrm{n}}\right)$,

Where $R$ is the radius of the cross section at the lower marker point $\left(R_{1}\right.$ is the radius of the cross section at the ankle marker point), $r$ is the radius of the cross section at the adjacent upper marker point, and $h$ is the distance between two adjacent marker points.

Volume difference $=$ affected limb volume - healthy limb volume;

Percent volume difference $=[($ affected limb volume - healthy limb volume $) /$ healthy limb volume $] \times 100 \%$ Volume of blood loss Pre-operative hemoglobin, post-operative hemoglobin and volume of intra-operative blood transfusion were recorded. Pre-operative blood volume was obtained based on the formula derived by Nadler et al [7]. Subsequently, volume of blood loss was calculated according to the formula derived by Budny et al [8].

Pre-operative blood volume $(\mathrm{ml})$ of men $=0.0003669 \times$ height $^{3}\left(\mathrm{~cm}^{3}\right)+[32.19 \times$ weight $(\mathrm{kg})+604]$

Pre-operative blood volume $(\mathrm{ml})$ of women $=0.0003561 \times$ height $^{3}\left(\mathrm{~cm}^{3}\right)+[33.08 \times$ weight $(\mathrm{kg})+183]$

Actual volume of blood loss $(\mathrm{ml})=$ pre-operative blood volume $\times$ [(pre-operative hemoglobin - postoperative hemoglobin) / pre-operative hemoglobin] + volume of intra-operative blood transfusion 
Others Record duration of operation, volume of aspirated fat and calculate the liposuction rate $($ Liposuction rate $=$ volume of aspirated fat/ duration of operation $)$.

The patient, female, 67 years old, secondary lymphedema of the left lower extremity. A:Preoperative.B:3 month after operation.

\section{Subjective evaluation}

At pre-operation and 3-month follow-up, patients filled out a questionnaire to evaluate their subjective feelings, which encompassed stiffness, tension, heaviness, tenderness, pain, numbness, fatigue and weakness.

\section{Statistical Analysis}

Data were presented as mean \pm standard deviation(Mean \pm SD). Kolmogorov-Smirnov test was performed to verify that the parameters conformed to normal distribution. The means of the two samples were compared by applying $t$-test of independent samples. Percent volume differences of the samples were compared by applying $t$-test of paired samples. A corrected $t$-test was employed when there was lack of variance. Chi-square was utilized to test the rate. $P<0.05$ was considered statistically significant. The data were analyzed using SPSS version 20.0 (IBM, Armonk, New York, USA).

\section{Results}

In this study, 62 cases were operated successfully without skin necrosis, subcutaneous effusion, infection or other complications(Fig. 1b, Fig. 2b). The operation time was (176 \pm 44.9$)$ min(range 110-300). The volume of aspirated fat was $(2539 \pm 1253.5) \mathrm{ml}$ (range $400-5,500)$. The estimated blood loss (EBL) was $(828 \pm 311.8) \mathrm{ml}($ range 224-1,585). Intra-operative homologous blood transfusion was performed in 3 patients. The liposuction rate was $14.8 \pm 7.7 \mathrm{ml} / \mathrm{mim}$ (range 1.0-30.0). The appearance of the lymphedematous extremity significantly improved at 3 months follow-up. Preoperative BMI was $26.7 \pm$ 4.2 , and 3 months follow-up BMI was $25.9 \pm 4$.0. This difference was not statistically significant $(t=1.038$, $P=0.301)$.

Percent volume differences at pre-operation, post-operation and 3 months follow-up were $(43.2 \pm 23.7) \%$, $(5.5 \pm 12.2) \%$ and $(11.6 \pm 18.4) \%$, respectively.Percent volume difference at post-operation and at 3-month follow-up significantly decreased compared with that at pre-operation $(P<0.05)$, but it significantly increased at 3-month follow-up compared with that at post-operation $(P<0.05)$.

Fat volume and liposuction rate were higher in female than those in male; whereas EBL, percent volume difference at pre-operation, post-operation and 3 months follow-up were higher in male than those in female(Table 1). EBL was higher in erysipelas group than that in non-erysipelas group(Table 2). Volume of aspirated fat and liposuction rate were higher in Stage II than those in Stage III group. In contrast, EBL, percent volume difference at pre-operation, post-operation and 3 months follow-up were lower in Stage II group (Table 3). 
Table 1

Comparison of surgical results between male and female patients with secondary lymphedema of lower extremities (Mean \pm SD)

\begin{tabular}{|lllll|}
\hline & Male & Female & t & Pvalue \\
\hline $\mathrm{N}$ & 16 & 46 & - & - \\
\hline Volume of blood loss $(\mathrm{ml})$ & $986 \pm 346$ & $774 \pm 282$ & 2.434 & 0.018 \\
\hline Volume of aspirated fat $(\mathrm{ml})$ & $1659 \pm 1223$ & $2845 \pm 1122$ & -3.559 & 0.001 \\
\hline Liposuction rate $(\mathrm{ml} / \mathrm{mim})$ & $8.8 \pm 5.9$ & $16.9 \pm 7.2$ & -4.013 & 0.000 \\
\hline Percent volume difference & & & & \\
\hline pre-operation (\%) & $56.8 \pm 22.1$ & $38.4 \pm 22.6$ & 2.807 & 0.007 \\
\hline post-operation (\%) & $16.5 \pm 13.7$ & $1.7 \pm 9.1$ & 4.034 & 0.001 \\
\hline 3 month follow-up (\%) & $22.9 \pm 18.6$ & $7.7 \pm 16.9$ & 3.024 & 0.004 \\
\hline
\end{tabular}

Table 2

Comparison of surgical results between erysipelas and non-erysipelas group with secondary lymphedema of lower extremities(Mean \pm SD)

\begin{tabular}{|lllll|}
\hline & erysipelas & non-erysipelas & t & P value \\
\hline $\mathrm{N}$ & 20 & 42 & - & - \\
\hline Volume of blood loss $(\mathrm{ml})$ & $1000 \pm 315$ & $747 \pm 278$ & 3.201 & 0.002 \\
\hline Volume of aspirated fat $(\mathrm{ml})$ & $2982 \pm 1412$ & $2328 \pm 1127$ & 1.965 & 0.054 \\
\hline Liposuction rate $(\mathrm{ml} / \mathrm{mim})$ & $16.3 \pm 7.7$ & $14.1 \pm 7.7$ & 1.057 & 0.295 \\
\hline Percent volume difference & & & & \\
\hline pre-operation (\%) & $49.0 \pm 27.5$ & $40.4 \pm 21.5$ & 1.343 & 0.184 \\
\hline post-operation (\%) & $7.3 \pm 13.7$ & $4.6 \pm 11.5$ & 0.808 & 0.422 \\
\hline 3 month follow-up (\%) & $14.9 \pm 17.9$ & $10.1 \pm 18.7$ & 0.951 & 0.346 \\
\hline
\end{tabular}


Table 3

Comparison of surgical results between stage II and stage III group with secondary lymphedema of lower extremities(Mean \pm SD)

\begin{tabular}{|lllll|}
\hline & stage II & stage III & t & P value \\
\hline N & 29 & 33 & - & - \\
\hline Volume of blood loss $(\mathrm{ml})$ & $689 \pm 249$ & $950 \pm 313$ & -3.598 & 0.001 \\
\hline Volume of aspirated fat $(\mathrm{ml})$ & $2875 \pm 1247$ & $2243 \pm 1199$ & 2.031 & 0.047 \\
\hline Liposuction rate (ml/mim) & $18.0 \pm 8.4$ & $12.1 \pm 6.0$ & 3.189 & 0.002 \\
\hline Percent volume difference & & & & \\
\hline pre-operation (\%) & $28.1 \pm 18.4$ & $56.5 \pm 19.7$ & -5.821 & 0.000 \\
\hline post-operation (\%) & $-3.2 \pm 6.2$ & $13.3 \pm 10.9$ & -7.438 & 0.000 \\
\hline 3 month follow-up (\%) & $1.7 \pm 15.3$ & $20.4 \pm 16.6$ & -4.576 & 0.000 \\
\hline
\end{tabular}

Feeling of heaviness and fatigue of the operated limb was alleviated at 3-month follow-up compared with that at pre-operation, whereas feeling of stiffness, tenderness and tightness worsened.There were no significant differences in pain, numbness and weakness between pre-operation and 3- month followup(Table 4).

Table 4

Comparison of subjective sensation between pre-operation and 3 months follow-up in 62 patients with secondary lymphedema of the lower extremity [case (\%)]

\begin{tabular}{|lllll|}
\hline & pre-operation & 3 month follow-up & Х2 & P value \\
\hline stiffness & $25(40.3)$ & $36(58.1)$ & 3.904 & 0.048 \\
\hline tightness & $19(30.6)$ & $35(56.4)$ & 8.398 & 0.004 \\
\hline heaviness & $49(80.6)$ & $34(54.8)$ & 9.448 & 0.002 \\
\hline tenderness & $5(7.9)$ & $13(21.0)$ & 4.305 & 0.038 \\
\hline pain & $6(9.7)$ & $13(21.0)$ & 3.046 & 0.081 \\
\hline numbness & $33(53.2)$ & $41(66.1)$ & 2.145 & 0.143 \\
\hline fatigue & $44(71.0)$ & $27(43.5)$ & 9.523 & 0.002 \\
\hline weakness & $7(11.3)$ & $11(17.7)$ & 1.040 & 0.308 \\
\hline
\end{tabular}

\section{Discussion}


In the world, secondary lymphedema most commonly occurs following treatment of cancer. A variety of conservative therapies have been reported, including complete decongestion therapy(CDT)[9], as well as microsurgical reconstruction including lymhatic venous anastomosis[10] or lymph node transplantation[11, 12].Failure of these treatments to provide complete reduction in patients with longstanding pronounced lymphedema is due to the persistence of excess newly formed subcutaneous adipose tissue in response to slow or absent lymph flow, which is not removed in patients with chronic lymphedema. Liposuction has drawn increased attention in the surgical treatment of lymphedema because it can remove hypertrophied adipose tissue.

Here we have demonstrated that liposuction surgery improved both quality of life and volumetric measurements in patients with lymphedema. Overall, the percent volume difference was significantly lower at post-operation and 3 months follow-up than that at pre-operation. The mean estimated blood loss (EBL) was $828 \mathrm{ml}$, which was much higher than the EBL of $292 \mathrm{ml}$ when liposuction was done in obese patients[13]. The reason may be that there is abnormal hyperplasia of subcutaneous adipose tissue in lymphedematous limbs, and that the proliferating adipose layer contains multiple septations, which poses more difficulty during liposuction of lymphedematous limbs, aggravates peripheral vascular injury and increases bleeding than conventional liposuction. Therefore, patients with anemia should be proactively corrected before liposuction. Some patients may need packed red blood cells (pRBC) prepared before surgery. In this study, 3 patients were given intra-operative homologous blood transfusion.

Male had a significantly higher percent volume difference than female at pre-operation, post-operation, and 3 months follow-up, but significantly lower volume of aspirated fat and higher EBL. This suggests that there may be differences between male and female in the occurrence and development of lymphedema.Perhaps the abnormality of the lymphedematous lower extremity in male is more profound than that in female. In addition, subcutaneous tissue hyperplasia and fibrosis may aggravate as the disease progresses. We also found that the liposuction rate in male was significantly lower than that in female during the operation. That is, it was more difficult to extract fat in male. Moreover, the effect of different hormone levels between male and female on the composition of subcutaneous tissue [14, 15]as well as poor compliance of male may also account for the aforementioned differences, which need to be further investigated.

Lymphedema is one of the risk factors for the occurrence of erysipelas [16].Recurrent erysipelas can lead to subcutaneous tissue fibrosis, which in turn can aggravate lymphedema. In the study of Kosenkov[17], a correlation was found between occurrence of erysipelas and the degree of lymphedema, and they aggravated each other.In our study, the erysipelas group was noted to have higher EBL than the nonerysipelas group. This suggests that patients with recurrent erysipelas may have more fibrosis in the subcutaneous tissue, which could increasethe difficulty and risk of the surgery.

The percent volume difference of Stage $\nabla$ group was significantly higher than that of Stage $\otimes$ group at preoperation, post-operation, and 3-month follow-up, whereas the volume of aspirated fat and liposuction rate of Stage III group was significantly lower than those of Stage II group. In addition, EBL of Stage III 
group is greater than that of Stage II group. These results suggest that, the longer the disease period, the more difficult the liposuction may become, and the more blood loss may ensue. It can be deduced that the surgical outcome may also be worse.The reason may be that the degree of fibrosis of subcutaneous tissue gradually elevates along the course of the disease. Sun et al[18] also believe that skin hardness is positively correlated with stage of lymphedema. Consequently, the outcome of liposuction and volume reduction in advanced limb lymphedema may not be as good as those in early lymphedema.

Regarding subjective feelings of the patients, the feeling of heaviness and fatigue of the affected limbs significantly reduced at 3-month follow-up compared with that at pre-operation, but the feeling of stiffness, tenderness and tightness of the lymphedematous limb was more severe than that at preoperation. This may be related to the injury of subcutaneous nerves and inflammatory reactions after liposuction. It is worth noting that $58.1 \%$ of patients still felt stiff, $56.4 \%$ felt tight and $54.8 \%$ felt heavy 3 months after liposuction. The reason may be that the compression stocking fails to effectively improve lymphatic circulation despite significantly reduced volume of the lymphedematous limb after liposuction.

The data also show that percent volume difference increases significantly at 3-month follow-up after liposuction, which is consistent with the subjective sensory changes of the patients. Qi et al[4] compared outcome of liposuction in 17 patients - 7 upper limb lymphedema and 10 lower limb lymphedema. Substantial limb volume reduction was noted in all cases immediately after operation. This state of volume reduction remained 3 to 12 months with a mean of 6.01 months by applying low-stretch bandages or compression stockings. Subsequently it returned to the preoperative volume level. This implies that liposuction combined with more effective post-operative measures to ameliorate lymphatic circulation could contribute to a better surgical outcome of extremity lymphedema.

In our study, all cases were treated with a second-stage surgery within 3 to 6 months after liposuction to improve lymphatic circulation. All cases are still being followed up.

\section{Conclusions}

Liposuction demonstrates certain positive effects on treatment of the cancer-related lower extremity lymphedema. Nevertheless, compared with traditional liposuction in plastic surgery, it is more risky and difficult and should be combined with more effective methods to improve lymphatic circulation in the early post-operative period. Moreover, gender differences, history of erysipelas and stage of the disease should be taken into account during the treatment process, especially during the perioperative period.

\section{Abbreviations}

EBL: mean estimated blood loss ; CCT: controlled compression therapy

\section{Declarations}

\section{Ethics approval and consent to participate}


Any repository data used in this study are open access and do not require any permissions. Ethics approval and consent to participate are not applicable for them.

\section{Consent for publication}

Not applicable.

\section{Availability of data and materials}

Not applicable.

\section{Competing interests}

The authors declare that they have no competing interests.

\section{Funding}

This project was supported by Beijing Municipal Science \& Technology Commission No. Z191100007619049. The funder is the corresponding author of the study and is responsible for the overall design and planning of this study.

\section{Authors' contributions}

All authors made substantial contributions to the conception and design of the study. The authors read and approved the final manuscript.

\section{Acknowledgements}

Not applicable.

\section{References}

1. Illouz YG. Une nouvelle technique pour les lipodystrophies localises. Rev Chir Esthet. 1980;4(1):19.

2. Brorson H. From lymph to fat: liposuction as a treatment for complete reduction of lymphedema. Int J Low Extrem Wounds. 2012;11(1):10-9.

3. Boyages J, Kastanias K, Koelmeyer LA, Winch CJ, Mackie H. Liposuction for advanced lymphedema: a multidisciplinary approach for complete reduction of arm and leg swelling. Ann Surg Oncol. 2015;22(Suppl 3):1263-70.

4. Qi FZ, Yang YW, Gu JY, SHI YD. The Long Term Efficacy of the Pure Liposuction Treatment for Patiens with Limb Lymphoedema. Clinical Medical Journal of China. 2008;15(1):89-91.

5. International Society of Lymphology. The diagnosis and treatment of peripheral lymphedema: 2013 Consensus Document of the International Society of Lymphology. Lymphology.2013;46(1):1-11. 
6. Brorson H, Hoijer P. Standardised measurements used to order compression garments can be used to calculate arm volumes to evaluate lymphoedema treatment. J Plast Surg Hand Surg. 2012;46(6):410-5.

7. Nadler SB, Hidalgo JH, Bloch T. Prediction of blood volume in normal human adults. Surgery. 1962;51(2):224-32.

8. Budny PG, Regan PJ, Roberts AH. The estimation of blood loss during burns surgery. Burns. 1993;19(2):134-7.

9. Mette Tambour M, Holt A, Speyer R, Christensen B, Gram. Manual lymphatic drainage adds no further volume reduction to Complete Decongestive Therapy on breast cancer-related lymphoedema: a multicentre, randomised, single-blind trial. Br J Cancer. 2018;119(10):1215-22.

10. AlJindan FK, Lin CY, Cheng MH. Comparison of Outcomes between Side-to-End and End-to-End Lymphovenous Anastomoses for Early-Grade Extremity Lymphedema[J]. Plast Reconstr Surg. 2019;144(2):486-96.

11. Gould DJ, Mehrara BJ, Neligan P, Cheng MH, Patel KM. Lymph node transplantation for the treatment of lymphedema. J Surg Oncol. 2018;118(5):736-42.

12. Koide $\mathrm{S}$, Lin $\mathrm{CY}$, Chen $\mathrm{C}$, Cheng $\mathrm{MH}$. Long-term outcome of lower extremity lymphedema treated with vascularized lymph node flap transfer with or without venous complications. J Surg Oncol. 2020;121(1):129-37.

13. Swanson E. Does laser assistance reduce blood loss after liposuction? Aesthet Surg J. 2015;35(2):38-9.

14. de la Casa AM, Suarez SC, Rebollo RJ, JiménezRejano. Cellulite's aetiology: a review. J Eur Acad Dermatol Venereol. 2013;27(3):273-8.

15. Xiao Z, Guo B, Gong J, Tang Y, Shang J, Cheng Y, et al. Sex-and age-specific percentiles of body composition indices for Chinese adults using dual-energy $\mathrm{X}$-ray absorptiometry. Eur $\mathrm{J}$ Nutr. 2017;56(7):2393-406.

16. Inghammar M, Rasmussen M, Linder A. Recurrent erysipelas-risk factors and clinical presentation. BMC Infect Dis. 2014;14:270.

17. Kosenkov AN, Narenkov VM, Abramov I. Erysipelas as the cause of lymphedema. Khirurgiia (Mosk).2005(11):51-53.

18. Sun D, Yu Z, Chen J, Wang L, Han L, Liu N. The value of using a Skin FibroMeter for diagnosis and assessment of secondary lymphedema and associated fibrosis of lower limb skin. Lymphat Res Biol. 2017;15(1):70-6.

\section{Figures}




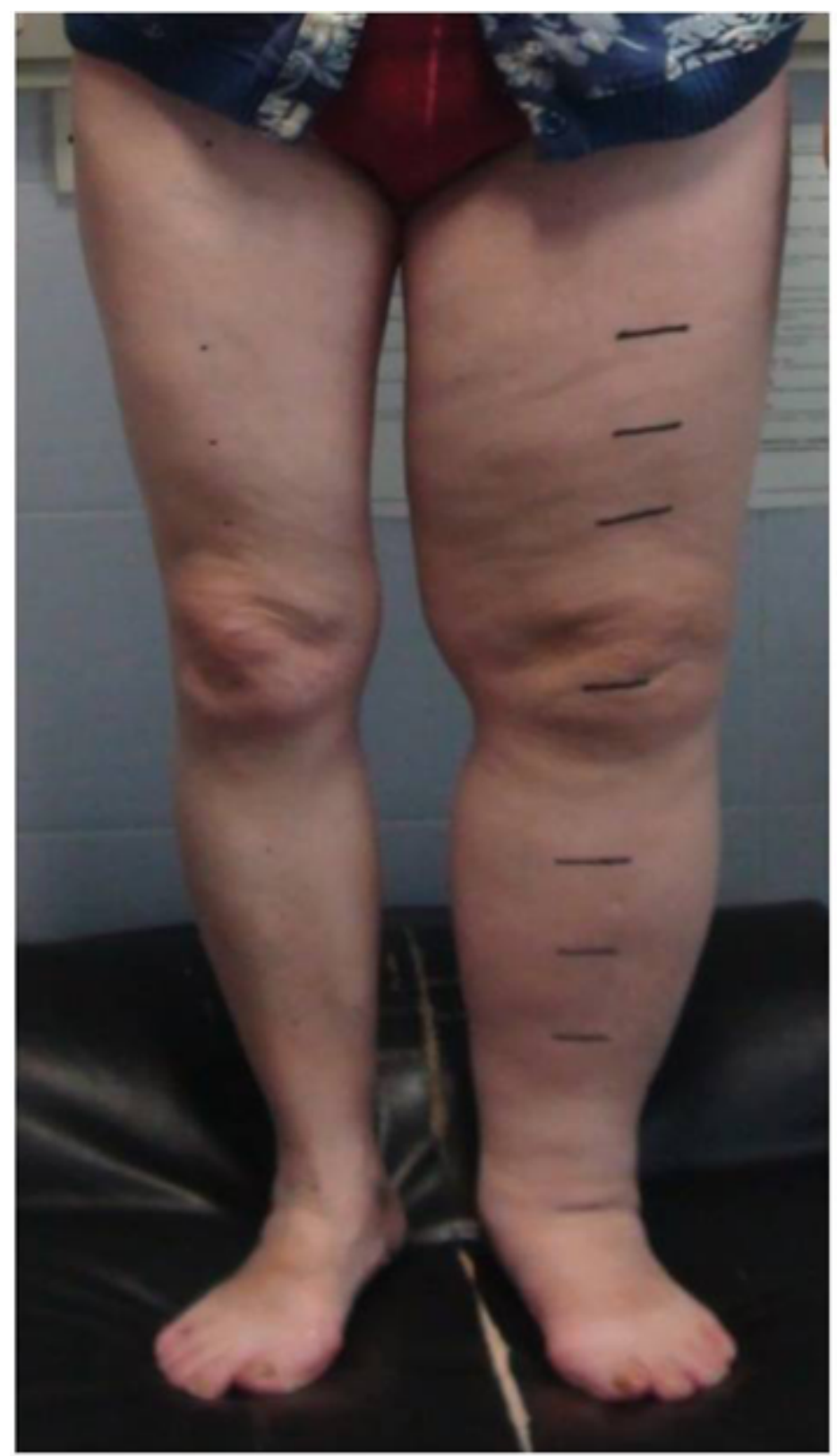

Fig-1a

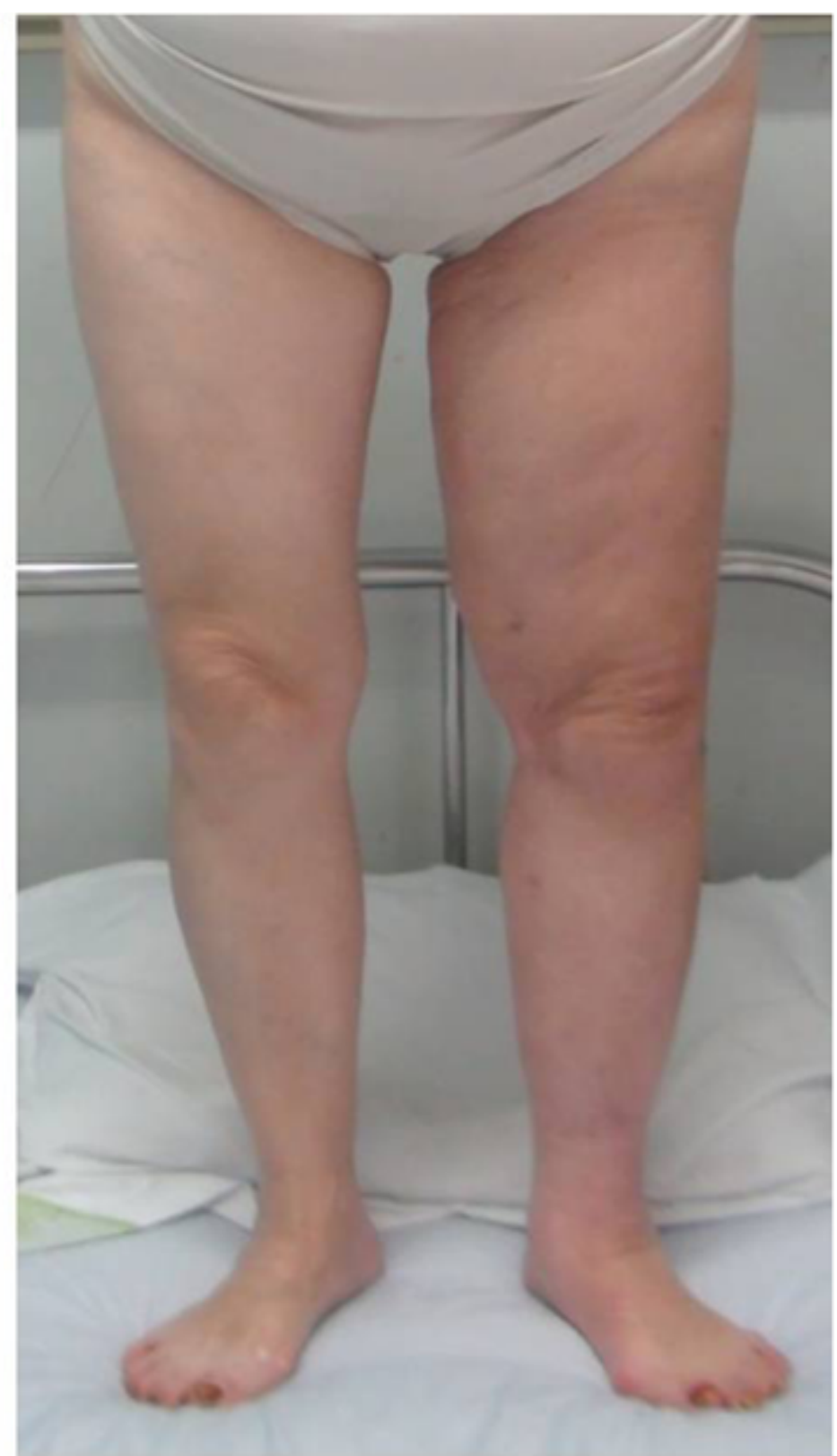

Fig.1b

\section{Figure 1}

The patient, female, 67 years old, secondary lymphedema of the left lower extremity. A:Preoperative.B:3 month after operation. 


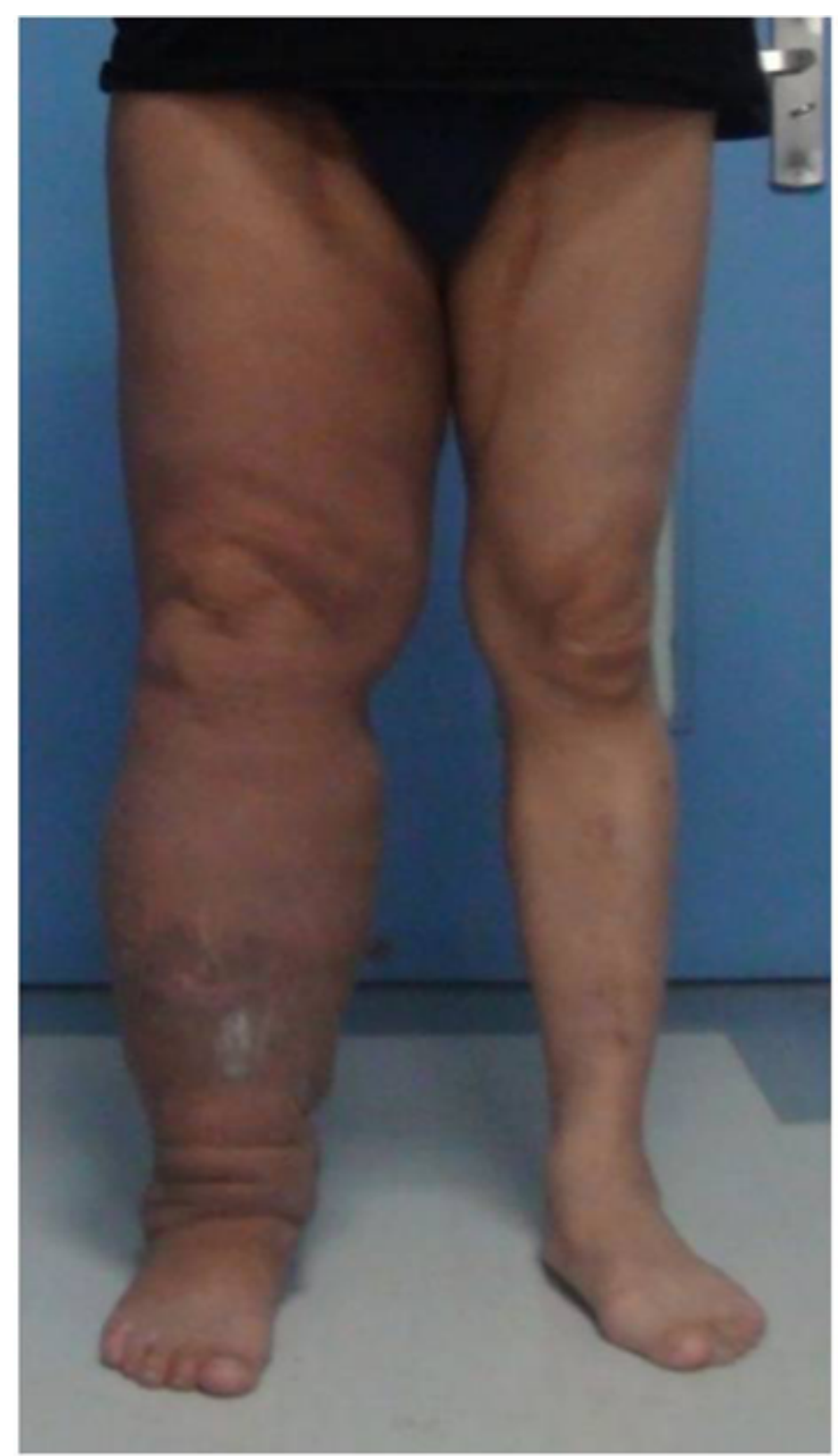

Fig.2a

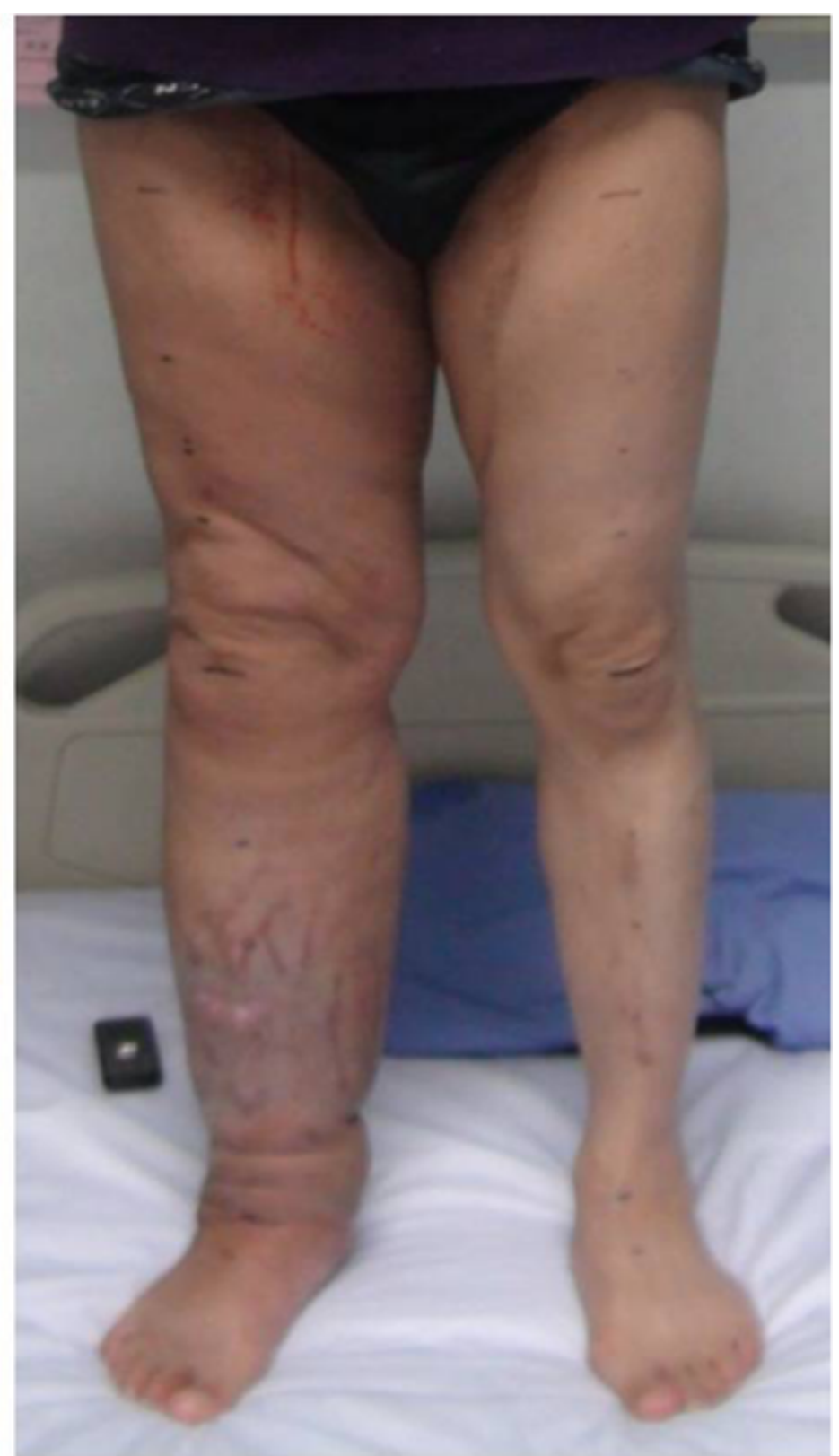

Fig.2b

\section{Figure 2}

The patient, male, 55 years old, secondary lymphedema of the right lowerextremity. A:Preoperative.B:3 month after operation. 